\title{
Presence of Legionella spp. in Hot Water Networks of Different Italian Residential Buildings: A Three-Year Survey
}

\author{
Michele Totaro ${ }^{1}$, Paola Valentini ${ }^{1}$, Anna Laura Costa ${ }^{1}$, Lorenzo Frendo ${ }^{1}$, Alessia Cappello ${ }^{1}$, \\ Beatrice Casini ${ }^{1}$, Mario Miccoli ${ }^{2}$, Gaetano Privitera ${ }^{1}$ and Angelo Baggiani ${ }^{1, *}$ \\ 1 Department of Translational Research N.T.M.S., University of Pisa, 56126 Pisa, Italy; \\ micheleto@hotmail.it (M.T.); paola.valentini@dps.unipi.it (P.V.); anna.costa@med.unipi.it (A.L.C.); \\ lorenzo.frendo@hotmail.com (L.F.); ale.cappello294@libero.it (A.C.); beatrice.casini@med.unipi.it (B.C.); \\ gaetano.privitera@med.unipi.it (G.P.) \\ 2 Department of Clinical and Experimental Medicine, University of Pisa, 56126 Pisa, Italy; \\ mario.miccoli@med.unipi.it \\ * Correspondence: angelo.baggiani@med.unipi.it
}

Received: 9 October 2017; Accepted: 23 October 2017; Published: 26 October 2017

\begin{abstract}
Although the European reports highlight an increase in community-acquired Legionnaires' disease cases, the risk of Legionella spp. in private houses is underestimated. In Pisa (Italy) we performed a three-year survey on Legionella presence in 121 buildings with an independent hot water production (IB); 64 buildings with a central hot water production (CB); and 35 buildings with a solar thermal system for hot water production (TB). From all the 220 buildings Legionella spp. was researched in two hot water samples collected either at the recirculation point or on the first floor and on the last floor, while the potable water quality was analysed in three cold water samples collected at the inlet from the aqueduct network, at the exit from the autoclave, and at the most remote tap. Legionella pneumophila sg1, Legionella pneumophila sg2-16, and non-pneumophila Legionella species were detected in $26 \%$ of the hot water networks, mostly in CB and TB. In these buildings we detected correlations between the presence of Legionella and the total chlorine concentration decrease and/or the increase of the temperature. Cold water resulted free from microbiological hazards, with the exception of Serratia liquefaciens and Enterobacter cloacae isolated at the exit from two different autoclaves. We observed an increase in total microbial counts at $22^{\circ} \mathrm{C}$ and $37^{\circ} \mathrm{C}$ between the samples collected at the most remote taps compared to the ones collected at the inlet from the aqueduct. The study highlights a condition of potential risk for susceptible categories of population and supports the need for measures of risk assessment and control.
\end{abstract}

Keywords: Legionella; residential buildings; water risk; community-acquired Legionnaire's disease cases

\section{Introduction}

Legionella spp. is a Gram-negative aerobic bacterium, which is widely present in soil and freshwater but that can also contaminate water systems; it replicates between $25{ }^{\circ} \mathrm{C}$ and $42{ }^{\circ} \mathrm{C}$ surviving at higher temperatures [1,2]. Legionella infection may cause distinct clinical diseases as Legionnaires' Disease and Pontiac fever. Infection is acquired by inhalation, aspiration, or micro-aspiration of Legionella-carrying aerosols. Droplets carrying the pathogen can originate by water spraying or by gurgling air through contaminated water. Immunocompromisation, chronic diseases, and old age are predisposing factors for the development of the disease [3]. Legionella pneumophila serogroup 1 is the species most commonly associated with the disease. It is the cause of $95 \%$ of Legionella infections in Europe and $85 \%$ worldwide [4-6]. The surveillance of legionellosis is coordinated in Europe by the European Centre 
for Disease Prevention and Control (ECDC), and in Italy by the Italian National Institute of Health. The latest data, related to 2015, give 1553 cases of legionellosis in the Italian population, corresponding to a notification rate of 2.55 cases per million inhabitants. However, it must be noted that 2015 has seen an increase of $5.6 \%$ in the cases when compared with the previous year. Of the 1553 notified cases, 83 (5.3\%) were hospital acquired, while 1221 (78.5\%) were community-acquired infections, underscoring the relevance of Legionella contamination of community environment and the subsequent need for control $[7,8]$. Considering the high percentage of Legionella community-acquired infections, Italian and European literature data on Legionella contamination in air conditioning systems and hot water networks are available both for hospitals [9,10], and for small residential buildings [11].

There are several studies reporting Legionella presence in water not associated with a specific outbreak; they include studies from Italy [12], Germany [13], Turkey [14], Georgia [15], Denmark [16], Poland [17], etc.

In Italy, in 2015 a guideline for legionellosis control in all the settings has been updated by the Italian Ministry of Health [18]. This technical document gives indications for prevention and control of Legionella in hot water networks with instructions for Legionella risk assessment in different contexts. Moreover, the Council Directive 98/83/EC [19] identifies the importance and the responsibilities for water quality control in buildings. In a previous study, a survey on 81 Italian apartments buildings found the colonization of Legionella in $20 \%$ of hot water networks [20]. Following the previous published data, the aim of this study is the assessment of Legionella colonization in hot water networks in residential buildings in the Pisa district (Italy) in the period 2014-2017.

\section{Materials and Methods}

\subsection{Setting and Inspections}

Following the requests of some building administrators of controlling the drinking water quality, the survey was performed from April 2014 to April 2017 on 220 residential buildings located in Pisa (Italy). Buildings are situated in different areas (old town, new town, industrial area, countryside, sea district, etc.). We investigated buildings with old and with new water networks. The buildings were mainly of small sizes with a range between four and twenty flats. One-hundred twenty-one buildings had an independent hot water production (IB); 64 buildings had a central hot water production (CB); 35 buildings had a solar thermal system for hot water production (TB).

In each technical plant an inspection visit was performed with the aim of analysing the adequate functioning of the thermal and water power plants. Inspections were conducted following a checklist organized with some information such as name, address of building, type of hot water production system, presence of devices (recirculation, boilers, softeners, autoclaves, etc.), water disinfection system, periodicity and type of water system maintenance and cleaning, water supplying, and number of floors and apartments.

\subsection{Sampling}

From each water system three cold water samples were taken at the inlet from the aqueduct network into the building pipework (Point I); at the exit from pressure autoclave (point E); and at the most remote tap from the autoclave (point T). Therefore, 660 cold water samples were analysed for the determination of potability requirements as suggested by the Council Directive 98/83/EC [19].

At the same time two hot water samples were collected either at the recirculation point or on the first floor of the building (Point A) and on the last floor (Point B). Therefore, 440 hot water samples were collected for Legionella spp. detection as suggested by the Italian guidelines for legionellosis control.

Water temperature and total chlorine concentration, were determined in cold and hot water samples, while $\mathrm{pH}$, and conductivity values were measured only in hot water samples. 


\subsection{Laboratory Tests}

In accordance to the Council Directive 98/83/EC [19] total microbial count at $22{ }^{\circ} \mathrm{C}$ and at $37^{\circ} \mathrm{C}$, coliforms and enterococci counts were determined. Total microbial count was performed in Reasoner's 2A agar (Oxoid Ltd., Basingstoke, Hampshire, UK) according to ISO6222:2001 [21]. Coliforms and enterococci bacteria were researched in $100 \mathrm{~mL}$ samples using Colilert $100 \mathrm{~mL}$ (Idexx, Westbrook, ME, USA) and Slanetz Bartley Agar (Biolife, Milan, Italy), respectively, according to ISO 9308-1:2012 [22] and ISO 7899-2:2003 [23]. Bacteria species confirmation of suspect colonies was obtained by Mini API galleries (bioMeriéux, Marcy l'Etoile, France).

The samples were tested for the presence of Legionella in accordance to the Italian guidelines and ISO 11731:1998 [24]. One litre of water was filtered through a $0.2 \mu \mathrm{m}$ membrane (Millipore, Billerica, MA, USA), which was subsequently immersed in $10 \mathrm{~mL}$ of the same water and sonicated for $5 \mathrm{~min}$, allowing the detachment of cells from the membrane and their suspension in water. Suspension was subjected to a thermal inactivation treatment at $50{ }^{\circ} \mathrm{C}$ for $30 \mathrm{~min}$ with the aim to select Legionella spp., inactivating all the microbial species not resistant to high temperature. Afterwards, $0.1 \mathrm{~mL}$ of the suspension was seeded in triplicate on Legionella selective medium (cefamandole, polymyxin B, anisomycin) (Oxoid Ltd., Basingstoke, Hampshire, UK) and the plates were incubated at $37^{\circ} \mathrm{C}$ for $7-10$ days within jars containing modified atmosphere $\left(2.5 \% \mathrm{CO}_{2}\right)$. Suspected Legionella colonies grown on the medium were subjected to species and serogroup identification analysis using a multi-purpose latex agglutination test (Legionella Latex Test, Oxoid Ltd., Basingstoke, Hampshire, UK).

\subsection{Statistical Analysis}

The Shapiro-Wilk test was performed to verify normality of distributions. The Kruskall-Wallis test and the Dunn's test were performed to compare the total microbial counts at $22{ }^{\circ} \mathrm{C}$ and at $37^{\circ} \mathrm{C}$ detected in different sampling points. Power tests were used to estimate the sample sizes, the 1- $\beta$ values of the significant variables were $>0.8$, assuring a low risk of type II error and an appropriate sample sizes. Correlation tests were performed, and Pearson's coefficients were calculated with the aim to analyse the correlations between physical-chemical parameters of the samples (temperature, chlorine concentration, and conductivity) and the presence of Legionella spp. These tests were independently applied for IB, CB, and TB. Confidence levels of 95\% were defined for the statistical tests. Therefore, we considered the following ranges of values: $0-0.3$ (weak correlation); 0.3-0.7 (moderate correlation); 0.7-1 (strong correlation). All statistical analysis was carried out using the SPSS software package (version 17.0.1, IBM, Armonk, NY, USA).

\section{Results}

\subsection{Inspections and Physical-Chemical Results}

All 121 IB present an autoclave system which collects municipal water before being injected in water networks. Water is softened in 36 out of $121(30 \%)$ buildings. Cold water (mean $19.3 \pm 2.1{ }^{\circ} \mathrm{C}$ ) is disinfected with sodium hypochlorite, which was detected at points of use (Point I, Point E, and Point T) in a concentration range between 0 and $0.21 \mathrm{mg} / \mathrm{L}$ (mean $0.11 \pm 0.06 \mathrm{mg} / \mathrm{L}$ ). In these buildings each flat has an independent boiler for hot water production. Hot water $\left(42.7 \pm 12.1^{\circ} \mathrm{C}\right)$ is treated with sodium hypochlorite at concentration between 0 and $0.24 \mathrm{mg} / \mathrm{L}$ (mean $0.18 \pm 0.09 \mathrm{mg} / \mathrm{L}$ ) measured at Point $\mathrm{A}$ and Point B. Physical-chemical data, measured in hot water samples, showed $\mathrm{pH}$ values ranging from 5.7 to 7.3 (mean $6.5 \pm 0.9$ ) and conductivity values between 344 and $1089 \mu \mathrm{S}$ (mean $797 \pm 233 \mu \mathrm{S}$ ). Maintenance and cleaning activities of the central water supplies are performed on a half-yearly basis.

On the other hand, all 64 CB have an autoclave system, which distribute municipal water. Only 16 out of $64(28 \%)$ central water supplies are provided with a softener. Sodium hypochlorite is the disinfectant used for cold and hot water treatment and its concentration, detected at points of use, ranged from 0 to $0.1 \mathrm{mg} / \mathrm{L}$ (mean $0.04 \pm 0.03 \mathrm{mg} / \mathrm{L}$ ) in cold water $\left(18.6 \pm 2.6{ }^{\circ} \mathrm{C}\right.$ ), and from 0 to $0.15 \mathrm{mg} / \mathrm{L}$ (mean $0.07 \pm 0.05 \mathrm{mg} / \mathrm{L})$ in hot water $\left(44.2 \pm 7.2^{\circ} \mathrm{C}\right.$ ). All buildings have a thermal central 
water system with a recirculation device, aimed to energy saving. Physical-chemical data, measured in hot water samples, showed $\mathrm{pH}$ values ranging from 5.9 to 7.5 (mean of $6.7 \pm 1.1$ ) and conductivity values between 344 and $1081 \mu \mathrm{S}$ (mean of $799 \pm 241 \mu \mathrm{S}$ ). Maintenance and cleaning activities of the cold and hot water systems are performed on a half-yearly basis.

Regarding the TB, all the 35 central water supplies have an autoclave system. Thirty out of $35(86 \%)$ water plumbing distribute municipal water, while five out of $35(14 \%)$ of TB are fed by wells water. No buildings have softeners and an adequate disinfection method. Therefore, all cold water $\left(17.9 \pm 2{ }^{\circ} \mathrm{C}\right)$ and hot water $\left(37.4 \pm 8.2^{\circ} \mathrm{C}\right)$ samples from $\mathrm{TB}$ were not chlorinated. All central water supplies have a boiler device for water storage, heated by solar thermal systems. Physical-chemical data, measured in hot water samples, showed $\mathrm{pH}$ values ranging from 5.8 to 7.1 (mean $6.9 \pm 1$ ) and conductivity values between 1025 and $1100 \mu \mathrm{S}$ (mean $1052 \pm 115 \mu \mathrm{S}$ ). Maintenance programs results absent in all the TB.

All physical-chemical values regarding the cold and hot water samples, collected at different points of use, are shown in Table 1.

Table 1. Mean values of physical-chemical parameters (total chlorine, $\mathrm{pH}$, conductivity, and temperature) detected in hot and cold water sampled at different point of use (Point A, Point B, Point I, Point E, and Point T) of the buildings IB, CB and TB. NA = Not Applied.

\begin{tabular}{|c|c|c|c|c|c|}
\hline \multirow{2}{*}{$\begin{array}{l}\text { Physical-Chemical } \\
\text { Parameters }\end{array}$} & \multicolumn{2}{|c|}{ Hot Water Samples } & \multicolumn{3}{|c|}{ Cold Water Samples } \\
\hline & Point A & Point B & Point I & Point E & Point T \\
\hline \multicolumn{6}{|c|}{ Building with independent hot water production (IB) } \\
\hline Total Chlorine (mg/L) & $0.21 \pm 1.1$ & $0.15 \pm 0.07$ & $0.05 \pm 0.03$ & $0.17 \pm 0.08$ & $0.11 \pm 0.05$ \\
\hline $\mathrm{pH}$ & $6.4 \pm 0.8$ & $6.6 \pm 1.2$ & NA & NA & NA \\
\hline Conductivity $(\mu S)$ & $801 \pm 253$ & $784 \pm 203$ & NA & NA & NA \\
\hline Temperature $\left({ }^{\circ} \mathrm{C}\right)$ & $48.1 \pm 8.6$ & $39.9 \pm 15.3$ & $18.7 \pm 2.9$ & $19.5 \pm 2$ & $19.8 \pm 1.4$ \\
\hline \multicolumn{6}{|c|}{ Building with central hot water production (CB) } \\
\hline Total Chlorine (mg/L) & $0.09 \pm 0.07$ & $0.05 \pm 0.03$ & $0.03 \pm 0.02$ & $0.06 \pm 0.03$ & $0.05 \pm 0.04$ \\
\hline $\mathrm{pH}$ & $6.6 \pm 1$ & $6.7 \pm 1.2$ & NA & NA & NA \\
\hline Conductivity $(\mu S)$ & $791 \pm 235$ & $805 \pm 254$ & NA & NA & NA \\
\hline Temperature $\left({ }^{\circ} \mathrm{C}\right)$ & $48.3 \pm 7.9$ & $40.1 \pm 7$ & $17.4 \pm 2.2$ & $18.9 \pm 2.1$ & $16 \pm 1.4$ \\
\hline \multicolumn{6}{|c|}{ Building with solar thermal system for hot water production (TB) } \\
\hline Total Chlorine (mg/L) & 0 & 0 & 0 & 0 & 0 \\
\hline $\mathrm{pH}$ & $6.9 \pm 1$ & $6.9 \pm 1.1$ & NA & NA & NA \\
\hline Conductivity $(\mu S)$ & $793 \pm 215$ & $799 \pm 256$ & NA & NA & NA \\
\hline Temperature $\left({ }^{\circ} \mathrm{C}\right)$ & $39.5 \pm 8.9$ & $33.8 \pm 7.9$ & $17.4 \pm 2.6$ & $18.9 \pm 2.2$ & $17.6 \pm 2.9$ \\
\hline
\end{tabular}

\subsection{Drinking Water Parameters Results}

A variability in microbial growth at $22{ }^{\circ} \mathrm{C}$ and $37^{\circ} \mathrm{C}$ was observed among the cold-water samples. No significant difference in the total microbial counts at $22^{\circ} \mathrm{C}$ and $37^{\circ} \mathrm{C}$ was found between samples collected in IB, CB and TB. Overall, the total microbial counts at $22{ }^{\circ} \mathrm{C}$ and $37{ }^{\circ} \mathrm{C}$ were between 1 and $400 \mathrm{CFU} / \mathrm{mL}$. High bacterial counts $\left(>10^{2} \mathrm{CFU} / \mathrm{mL}\right.$ ) were detected in $13 \%$ (87 out of 660 ) of the samples, mostly at Point $\mathrm{E}$ and Point $\mathrm{T}$.

The total microbial counts at $22^{\circ} \mathrm{C}$ and $37^{\circ} \mathrm{C}$ detected at the inlet from the aqueduct (Point I) were significantly lower $(p<0.0001)$ than these recorded in samples obtained at the most remote tap from the autoclave (Point $\mathrm{T}$ ).

In $\mathrm{CB}$ and $\mathrm{TB}$, the cold water resulted free from microbiological hazards. Enterococci were not isolated in any sample, but Serratia liquefaciens (3 CFU/100 mL) and Enterobacter cloacae (4 CFU/100 mL) were isolated at the exit from two different pressure autoclaves. 


\subsection{Legionella spp. Results}

Legionella spp. was detected in 100 out of $440(23 \%)$ of the hot water samples examined. However, 22 out of $121(18 \%)$ IB, 24 out $64(38 \%)$ CB, and 12 out of $35(34 \%)$ resulted positive to Legionella. Overall, 58 out of 220 (26\%) examined buildings had at least one sample positive for Legionella. A slight increase of colonized buildings was detected in the period between 2014 and 2017 (from 20\% to 26\%). This may be due to both the increase of the samples number (from 81 in the first year to 220 in all the following three years) and the high percentage of colonized $\mathrm{TB}$, which were analysed only in the period 2016-2017.

In IB Legionella positive samples showed counts from $2 \times 10^{2}$ to $4.8 \times 10^{4} \mathrm{CFU} / \mathrm{L}$ (mean $1 \times 10^{4} \pm 1.6 \times 10^{3} \mathrm{CFU} / \mathrm{L}$ ). Legionella pneumophila sg1, Legionella pneumophila sg2-16; and Legionella spp. were, respectively, recovered in 12 out of $22(55 \%)$, four out of $22(18 \%)$, and six out of $22(27 \%)$ of the water samples.

In IB samples statistical results showed moderate correlations between the presence of Legionella and the total chlorine concentration decrease $(r=0.64 ; p=0.02)$ (Figure 1$)$.

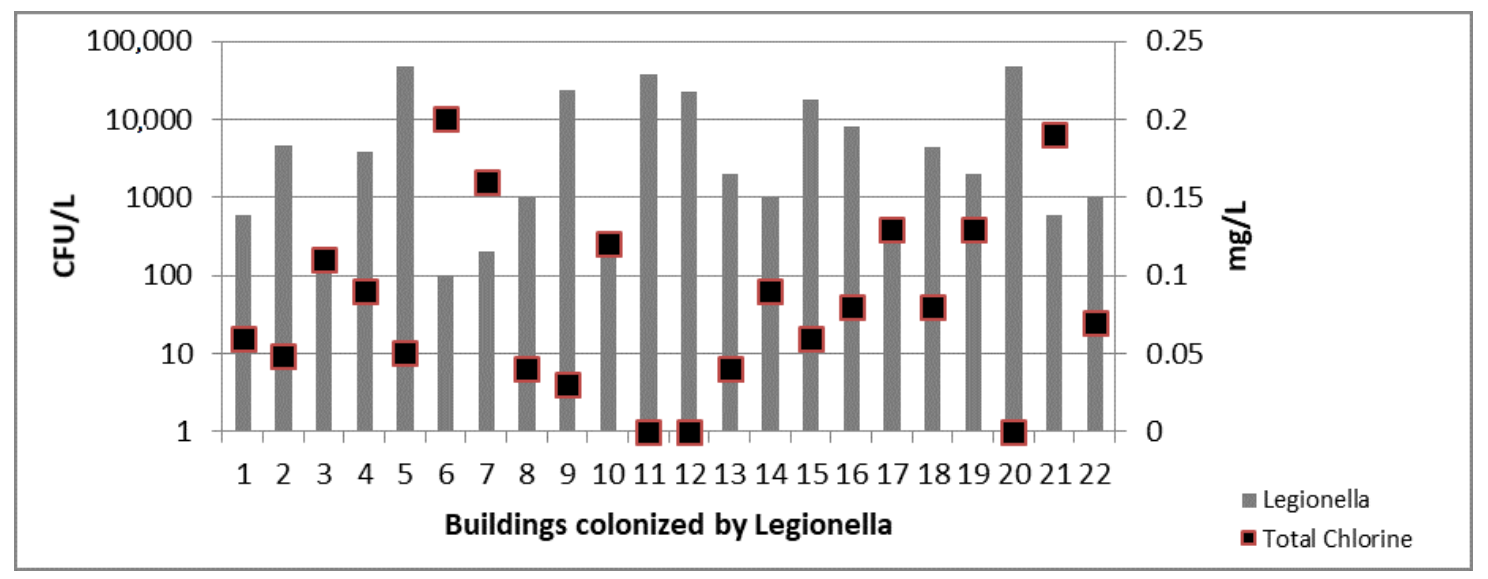

Figure 1. Legionella counts and total chlorine concentration detected in 22 colonized IB.

In CB Legionella positive samples showed counts between $2 \times 10^{2}$ and $3 \times 10^{4} \mathrm{CFU} / \mathrm{L}$ (mean $5.7 \times 10^{3} \pm 7.9 \times 10^{2} \mathrm{CFU} / \mathrm{L}$ ). Legionella pneumophila sg1, Legionella pneumophila sg2-16; and Legionella spp. were respectively recovered in nine out of 24 (38\%), eight out of $24(33 \%)$, and seven out of $24(29 \%)$ of the water samples.

In water samples collected from CB a moderate correlation was detected between the Legionella concentration and the reduction of total chlorine values $(r=0.67 ; p=0.022)$ (Figure 2).

Again, in CB samples a weak statistical correlation between the presence of Legionella and the increase of the temperature was obtained $(r=0.02 ; p=0.048)$ (Figure 3).

At last, in TB Legionella positive samples showed counts from $3 \times 10^{2}$ to $2.5 \times 10^{4} \mathrm{CFU} / \mathrm{L}$ (mean $5 \times 10^{4} \pm 7.1 \times 10^{2} \mathrm{CFU} / \mathrm{L}$ ). Legionella pneumophila sg1, Legionella pneumophila sg2-16; and Legionella spp. were respectively recovered in seven out of $12(58 \%)$, three out of $12(25 \%)$, and two out of $12(17 \%)$ of the water samples.

In water samples collected from TB a moderate correlation was detected between the Legionella concentration and the increase of the temperature $(r=0.6 ; p=0.02)$ (Figure 4$)$. 


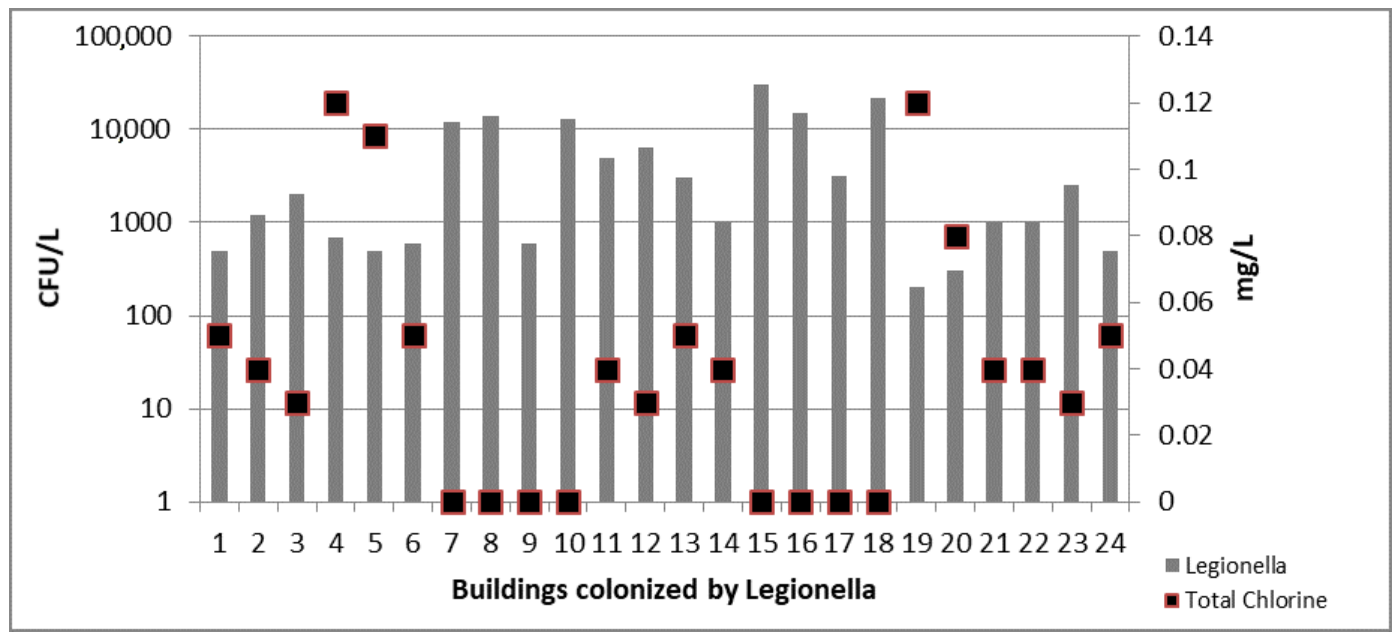

Figure 2. Legionella counts and total chlorine concentration detected in 24 colonized CB.

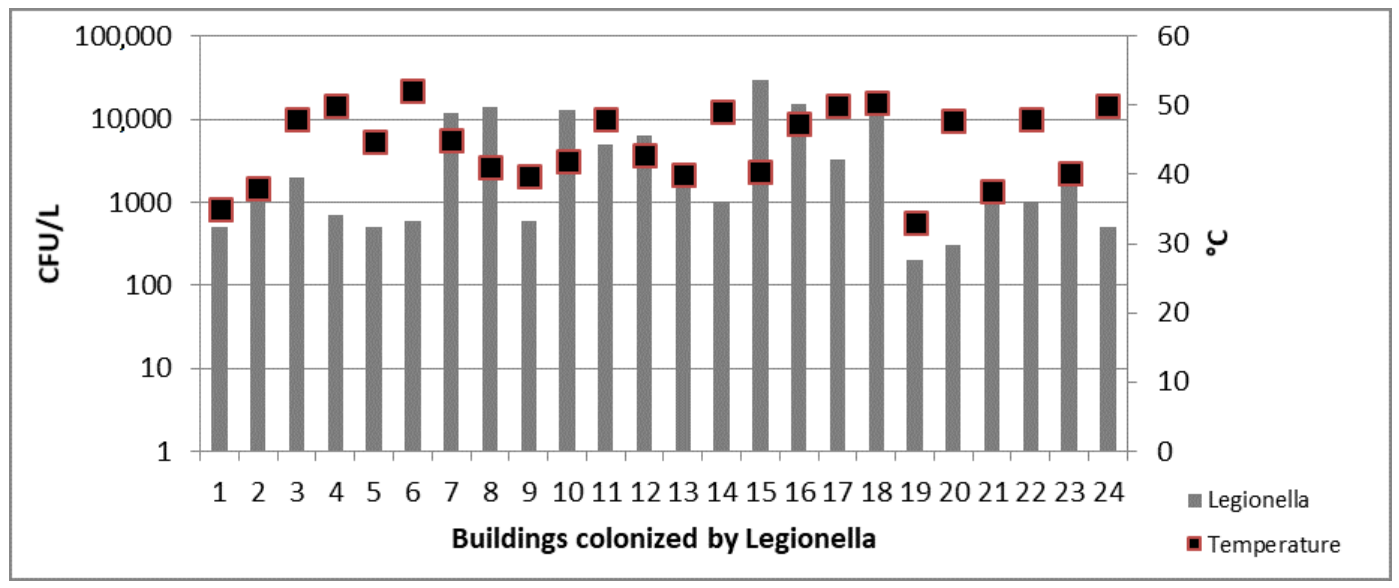

Figure 3. Legionella counts and temperature values detected in 24 colonized CB.

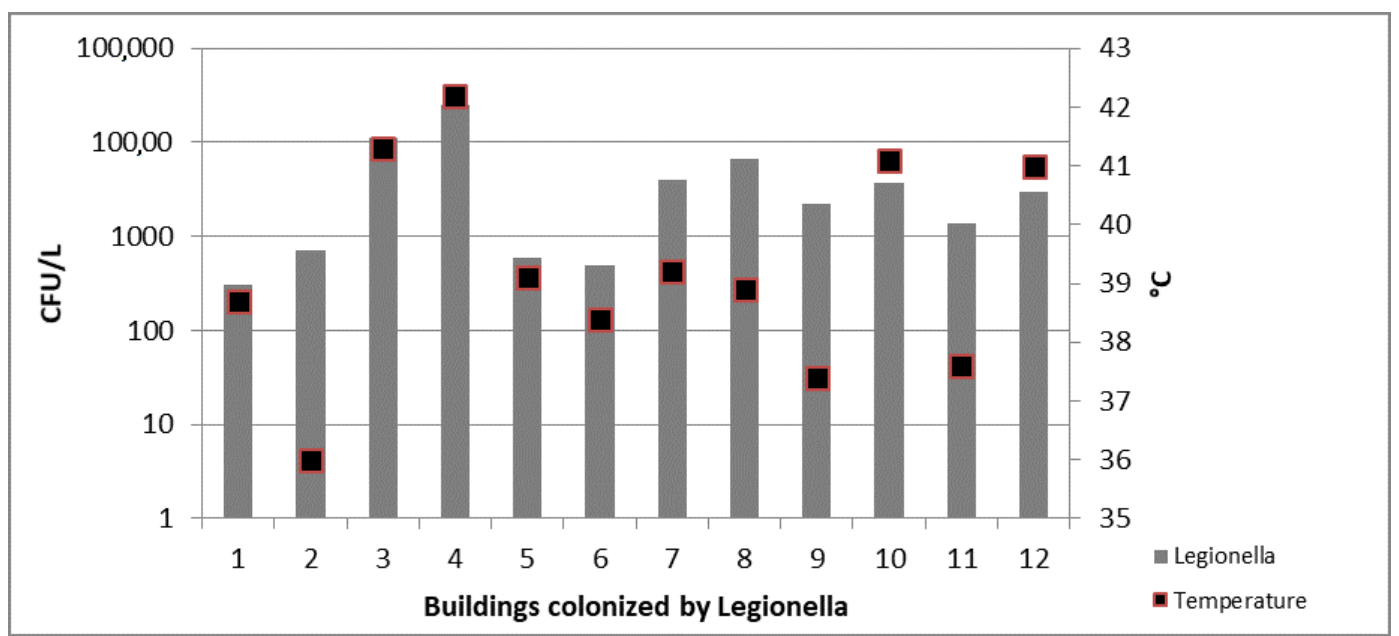

Figure 4. Legionella counts and temperature values detected in 12 colonized TB. 


\section{Discussion}

Despite water risk control is focused on evaluation of disinfection systems employed to control Legionella colonization in hospitals and tourist accommodations water networks, recent global epidemiological data show that almost $80 \%$ of the Legionnaire's disease cases diagnosed in a year are acquired in community $[7,8,25]$. In Italy, community cases are underestimated for the lack of specific diagnostic tests performed prior to prescribe broad-spectrum antibiotics. In community, the majority of Legionnaire's disease are considered as atypical pneumonia [20]. This evidence confirms the importance of extending prevention activities and water risk control to residential buildings not associated with a specific outbreak [11].

Home networks contamination represent a real risk for public health, especially for immunocompromised and elderly people. Moreover, European epidemiological data show that at least $50 \%$ of Legionella infections occurs in people under 65 , but a gradual rise of the incidence rates from the age of 40 is documented [8].

Our results, as well as other studies [26-28] demonstrate the presence of Legionella pneumophila sg1, Legionella pneumophila sg2-16, and non-pneumophila Legionella species in $26 \%$ of the hot water networks analysed, especially in buildings provided with a centralized warm water production system and a solar thermal system for hot water production. In these buildings we detected some moderate correlations between the presence of Legionella and the total chlorine concentration decrease and/or the temperature increase. Similar results were obtained in older studies. In particular, from 2004 to 2010 Italian literature data $[12,26,27]$ reveal the presence of Legionella pneumophila in small and large residential apartments in Italian cities, with percentages between $22.6 \%$ and $34 \%$. As described in our study the highest rate of Legionella colonization was detected in hot water networks of CB. In other European countries some slightly lower percentages of flat water networks colonization were obtained (12\%) [13,29]. As detected in our study, the European data show some correlations between the Legionella growth in pipework and the presence of specific water physical-chemical parameters, as the temperature of $44-48^{\circ} \mathrm{C}$, the absence of chemical disinfection and the $\mathrm{pH}$ values around $7.9[13,29,30]$.

Another issue evidenced by this study concerns the status of the autoclaves. Statistical data $(p<0.0001)$ show an increase in total microbial counts at $22^{\circ} \mathrm{C}$ and $37^{\circ} \mathrm{C}$ between the samples collected at the most remote tap from the autoclave compared to the ones directly sampled at the inlet from the aqueduct. Therefore, the higher microbial counts were obtained in water samples collected at distal points of use in apartments. This evidence may be due to sediment formation and debris deposition in the autoclave and in the pipework.

Although our data are similar to those published by other authors [12-17] and by our research group [20], this study highlights a Legionella related risk in TB, not mentioned in previous studies. This risk is due to the lack of water network maintenance and disinfection. These data provide a more complete evaluation of the Legionella hazard in different type of buildings located in the Pisa district.

\section{Conclusions}

In conclusion, our work is the first study evaluating the presence of Legionella and the potable water quality in three different types of residential buildings for a 36-month period, proving the need of water system control in residential apartments. The regulations of drinking water quality previously cited in this manuscript extend to building administrators the responsibility of hygienic water control in the building, from the point of delivery by the water supplier up to the points of use. Cold and hot water quality controls must be scheduled using a regular monitoring scheme of water networks to ensure public health safety. 
Acknowledgments: The study was not funded.

Author Contributions: Angelo Baggiani and Gaetano Privitera conceived and designed the experiments. Michele Totaro, Beatrice Casini, Paola Valentini, and Anna Laura Costa performed the experiments and wrote the paper. Mario Miccoli analysed the data. Lorenzo Frendo and Alessia Cappello performed the water samplings.

Conflicts of Interest: The authors declare no conflict of interest.

\section{References}

1. Rogers, J.; Dowsett, A.B.; Dennis, P.J.; Lee, J.V.; Keevil, C.W. Influence of temperature and plumbing material selection on biofilm formation and growth of Legionella pneumophila in a model potable water system containing complex microbial flora. Appl. Environ. Microbiol. 1994, 60, 1585-1592. [PubMed]

2. Bates, M.N.; Maas, E.; Martin, T.; Harte, D.; Grubner, M.; Margolin, T. Investigation of the prevalence of Legionella species in domestic hot water systems. N. Z. Med. J. 2000, 113, 218-220. [PubMed]

3. Fitzgeorge, R.B.; Baskerville, A.; Broster, M.; Hambleton, P.; Dennis, P.J. Aerosol infection of animals with strains of Legionella pneumophila of different virulence: Comparison with intraperitoneal and intranasal routes of infection. Epidemiol. Infect. 1983, 90, 81-89. [CrossRef]

4. Fields, B.S.; Benson, R.F.; Besser, R.E. Legionella and Legionnaire's disease: 25 years of investigation. Clin. Microbiol. Rev. 2002, 15, 506-526. [CrossRef] [PubMed]

5. Seenivasan, M.H.; Yu, V.L.; Muder, R.R. Legionnaires' disease in long-term care facilities: Overview and proposed solutions. J. Am. Geriatr. Soc. 2005, 53, 875-880. [CrossRef] [PubMed]

6. Diederen, B.M.W. Legionella spp. and Legionnaires' disease. J. Infect. 2008, 56, 1-12. [CrossRef] [PubMed]

7. Italian National Institute of Health. Rapporto Annuale Sulla Legionellosi in Italia Nel 2015; Italian National Institute of Health: Rome, Italy, 2016; Volume 29, pp. 1-28.

8. European Centre for Disease Prevention and Control. Legionnaires' Disease-Annual Epidemiological Report for 2015; European Centre for Disease Prevention and Control: Stockholm, Sweden, 2017; pp. 1-36.

9. Casini, B.; Buzzigoli, A.; Cristina, M.L.; Spagnolo, A.M.; Del Giudice, P.; Brusaferro, S.; Poscia, A.; Moscato, U.; Valentini, P.; Baggiani, A.; et al. Long-term effects of hospital water network disinfection on Legionella and other waterborne bacteria in an Italian university hospital. Infect. Control Hosp. Epidemiol. 2014, 35, $293-299$. [CrossRef] [PubMed]

10. Cristina, M.L.; Spagnolo, A.M.; Casini, B.; Baggiani, A.; Del Giudice, P.; Brusaferro, S.; Poscia, A.; Moscato, U.; Perdelli, F.; Orlando, P. The impact of aerators on water contamination by emerging gram-negative opportunists in at-risk hospital departments. Infect. Control Hosp. Epidemiol. 2014, 35, 122-129. [CrossRef] [PubMed]

11. Whiley, H. Legionella risk management and control in potable water systems: Argument for the abolishment of routine testing. Int. J. Environ. Res. Public Health 2016, 14, 12. [CrossRef] [PubMed]

12. Napoli, C.; Fasano, F.; Iatta, R.; Barbuti, G.; Cuna, T.; Montagna, M.T. Legionella spp. and legionellosis in southeastern Italy: Disease epidemiology and environmental surveillance in community and health care facilities. BMC Public Health 2010, 10, 660. [CrossRef] [PubMed]

13. Mathys, W.; Stanke, J.; Harmuth, M.; Junge-Mathys, E. Occurrence of Legionella in hot water systems of single-family residences in suburbs of two German cities with special reference to solar and district heating. Int. J. Hyg. Environ. Health 2008, 211, 179-185. [CrossRef] [PubMed]

14. Uzel, A.; Uçar, F.; Hameş-Kocabaş, E.E. Prevalence of Legionella pneumophila serogroup 1 in water distribution systems in Izmir province of Turkey. APMIS 2005, 113, 664-669. [CrossRef] [PubMed]

15. Moore, M.R.; Pryor, M.; Fields, B.; Lucas, C.; Phelan, M.; Besser, R.E. Introduction of monochloramine into a municipal water system: Impact on colonization of buildings by Legionella spp. Appl. Environ. Microbiol. 2006, 72, 378-383. [CrossRef] [PubMed]

16. Pringler, N.; Brydov, P.; Uldum, S. Occurrence of Legionella in Danish hot water systems. In Legionella; Marre, R., Abu Kwaik, Y., Bartlett, C., Cianciotto, N., Fields, B., Frosch, M., Hacker, J., Lück, P., Eds.; ASM: Washington, DC, USA, 2002; pp. 298-301.

17. Stojek, N.M.; Dutkiewicz, J. Co-existence of Legionella and other Gram-negative bacteria in potable water from various rural and urban sources. Ann. Agric. Environ. Med. 2011, 18, 330-334. [PubMed]

18. Italian National Institute of Health. Linee Guida per la Prevenzione ed il Controllo della Legionellosi; Italian National Institute of Health: Rome, Italy, 2015. 
19. The Council of the European Union. Council Directive 98/83/EC of 3 November 1998 on the Quality of Water Intended for Human Consumption; The Council of the European Union: Bruxelles, Belgium, 1998; pp. 1-23.

20. Baggiani, A.; Casini, B.; Totaro, M.; Aquino, F.; Valentini, P.; Bruni, B.; Porretta, A.; Casalini, F.; Miccoli, M.; Privitera, G. Colonization by Legionella spp. of water networks in residential buildings of the province of Pisa, Italy. Ann. Ig. 2014, 27, 718-725.

21. International Organization for Standardization. ISO 6222 Water Quality-Enumeration of Culturable Micro-Organisms-Colony Count by Inoculation in a Nutrient Agar Culture Medium; International Organization for Standardization: Geneva, Switzerland, 2001; pp. 1-4.

22. International Organization for Standardization. ISO 9308-2 Water Quality_Enumeration of Escherichia coli and Coliform Bacteria-Part 2: Most Probable Number Method; International Organization for Standardization: Geneva, Switzerland, 2012; pp. 1-45.

23. International Organization for Standardization. ISO 7899-2 Water Quality-Detection and Enumeration of Intestinal Enterococci-Part 2: Membrane Filtration Method; International Organization for Standardization: Geneva, Switzerland, 2000; pp. 1-7.

24. International Organization for Standardization. ISO 11731 Water Quality-Detection and Enumeration of Legionella; International Organization for Standardization: Geneva, Switzerland, 1998; pp. 1-38.

25. Garrison, L.E.; Kunz, J.M.; Cooley, L.A.; Moore, M.R.; Lucas, C.; Schrag, S.; Sarisky, J.; Whitney, C.G. Vital signs: Deficiencies in environmental control identified in outbreaks of Legionnaires' disease-North America, 2000-2014. Am. J. Transplant. 2016, 16, 3049-3058. [CrossRef] [PubMed]

26. Borella, P.; Montagna, M.T.; Romano-Spica, V.; Stampi, S.; Stancanelli, G.; Triassi, M.; Neglia, R.; Marchesi, I.; Fantuzzi, G.; Tatò, D.; et al. Legionella infection risk from domestic hot water. Emerg. Infect. Dis. 2004, 10, 457-464. [CrossRef] [PubMed]

27. Leoni, E.; De Luca, G.; Legnani, P.P.; Sacchetti, R.; Stampi, S.; Zanetti, F. Legionella waterline colonization: Detection of Legionella species in domestic, hotel and hospital hot water systems. J. Appl. Microbiol. 2005, 98, 373-379. [CrossRef] [PubMed]

28. Ryu, S.; Yang, K.; Chun, B.C. Community-acquired Legionnaires' disease in a newly constructed apartment building. J. Prev. Med. Public Health 2017, 50, 274-277. [CrossRef] [PubMed]

29. Dimitriadi, D.; Velonakis, E. Detection of Legionella spp. from domestic water in the prefecture of Arta, Greece. J. Pathog. 2014, 2014, 407385. [PubMed]

30. Zietz, B.; Wiese, J.; Brengelmann, F.; Dunkelberg, H. Presence of Legionellaceae in warm water supplies and typing of strains by polymerase chain reaction. Epidemiol. Infect. 2001, 126, 147-152. [PubMed] 